Artículo de reflexión E10A06. * Recibido 02-02-2017. * Aceptado versión final 19-10-2017. JEL: I18. Pp. 135-152

\title{
Encuentro entre Christophe Dejours y trabajadores chilenos. \\ Conversatorios sobre salud mental y sufrimiento en el trabajo.
}

Meeting between Christophe Dejours and chilean workers.

Conversations about mental health and suffering at work.

\author{
Pablo Zuleta Pastor
}

\section{CHILE}

\begin{abstract}
Resumen: Presentamos aquí un análisis y discusión del material producido en los Conversatorios de salud mental y sufrimiento en el trabajo, realizados como preparación para el encuentro entre Christophe Dejours y diferentes colectivos de trabajadores chilenos. Desde la voz de los trabajadores se van reconfigurando algunos conceptos clave de la Psicodinámica del trabajo: la distinción entre el hecho de trabajar y la organización del trabajo, la problemática del sufrimiento y la identidad, las patologías de la soledad y el suicidio en el trabajo, entre otras. Las líneas finales enfatizan en la doble centralidad del trabajo: sobre la subjetividad y sobre las relaciones sociales, planteando la relevancia de pensar y desarrollar en Chile perspectivas clínicas del trabajo.
\end{abstract}

Palabras clave: psicodinámica del trabajo; sufrimiento en el trabajo, organización del trabajo, clínicas del trabajo.

Abstract: We present here an analysis and discussion produced in the conversations of mental health and suffering at work done in preparation for the meeting between Christophe Dejours and different groups of chilean workers. From the voice of the workers, some key concepts of the Psychodynamics of work are re-configured:the distinction between the fact of working and the organization of work, the problem of suffering and identity, the pathologies of loneliness and suicide at work among others. The final lines emphasize in the double centrality of the work: on the subjectivity and on the social relations, raising the relevance of thinking and developing in Chile work clinics perspectives.

Keywords: psychodinamics of work; suffering at work; organization of work; work clinics.

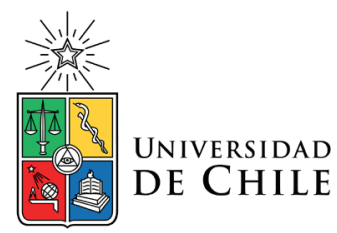

\footnotetext{
Pablo Zuleta es candidato a Doctor en Psicología en la Universidad de Chile, asociado a la Unidad Clínica del Trabajo y las Organizaciones del Centro de Psicología Aplicada (CAPs), y al Grupo de Investigación Tripalio: Salud mental y trabajo, de la Facultad de Ciencias Sociales de la Universidad de Chile.

Contacto: pzuletap@yahoo.es
} 


\section{Encontro entre Christophe Dejours e trabalhadores chilenos.}

Conversas sobre saúde mental e sofrimento no trabalho.

Resumo: Nós apresentamos aqui uma análise e discussão do material produzido nas palestras sobre a saúde mental e sofrimento no trabalho feito em preparação para o encontro entre Christophe Dejours e diferentes grupos de trabalhadores chilenos. Desde a voz dos trabalhadores vai (re) configuração de alguns conceitoschave da psicodinâmica do trabalho: a distinção entre o fato de trabalhar e de organização do trabalho, o problema do sofrimento e da identidade, as patologias de solidão e suicídio no trabalho, entre outros. As linhas finais enfatizar a centralidade do trabalho: na subjetividade e as relações sociais, elevando a importância de pensar e desenvolver perspectivas clínica do trabalho no Chile.

Palavras-chave: psicodinâmica do trabalho; sofrimento no trabalho; organização do trabalho; clínica do trabalho.

\section{Introducción}

1

n abril del año 2015 visitó Chile Christophe Dejours, fundador de la psicodinámica del trabajo. Su visita contempló variadas actividades académicas en la Universidad de Chile. En este marco, el grupo de trabajo e investigación en que participo, Grupo Tripalio: Salud mental y trabajo, en cooperación con otro colectivo, Panal, organizamos una de las actividades. Desde que tuvimos noticia de dicha posibilidad nuestra intención fue generar un espacio de diálogo entre el profesor y grupos de trabajadores chilenos. La discusión giró entonces en torno al diseño de un dispositivo orientado a comunicar e invitar a los trabajadores a un encuentro con Dejours, transmitiéndoles por qué podría ser significativo para ellos.

Barajamos varias fórmulas hasta que optamos por un dispositivo dialógico con base en una consigna simple: qué hacemos y qué nos pasa con lo que hacemos, que denominamos Conversatorios sobre salud mental y sufrimiento en el trabajo. Planteamos la pregunta y promovimos una escucha externa que favoreció la escucha propia y entre pares. Una escucha que, ante todo, vino a develar la falta de espacios de reflexión colectiva respecto del propio quehacer, la ausencia de espacios de elaboración de la experiencia laboral que en buena medida contempla la organización del trabajo contemporánea. En este sentido, consignamos esta ausencia no como mero olvido, sino como cuestión constitutiva de la organización del trabajo. Las experiencias expuestas por los trabajadores fueron escuchadas desde claves conceptuales dejourianas, pues la intención explícita del dispositivo era promover ese diálogo y convocar desde ahí a los trabajadores al encuentro con el autor. Nuestro trabajo fue "devolver" a los trabajadores sus experiencias de sufrimiento laboral, interpretadas desde el prisma ofrecido por Dejours. 
El texto que aquí presentamos cuenta con tres apartados. En el primero planteamos un marco referencial, lo más destacable es que se trata de una "selección y articulación conceptual" que surge del discurso de los trabajadores, pues es la narración de su experiencia la que va refiriendo, aunque sin consciencia de ello, algunos elementos del corpus teórico de la psicodinámica del trabajo. En el segundo organizamos los principales resultados de un análisis de contenidos producidos en los conversatorios, los que fueron agrupados en categorías de acuerdo con los procedimientos sugeridos por la teoría fundamentada de Glaser y Strauss (Flores y Naranjo, 2013) y luego puestos en diálogo con claves conceptuales de la psicodinámica del trabajo. En el tercer apartado aventuramos dos ideas finales que, más que cerrar, esperamos inviten a seguir pensando la pertinencia de las claves conceptuales ofrecidas por Dejours, tanto para comprender las situaciones de sufrimiento psíquico en el trabajo en Chile como para generar herramientas y/o dispositivos de acción para enfrentarlas.

\section{Marco de referencia}

\section{Distinciones entre trabajo y organización del trabajo}

Plantea Dejours, que "trabajar es colmar la brecha entre lo prescripto y lo efectivo. Es necesario repetirlo: el trabajo se define por aquello que el sujeto debe añadir a las prescripciones para alcanzar los objetivos que le son asignados o, incluso, lo que debe añadir de sí mismo para hacer frente a lo que no funciona cuando se atiene escrupulosamente a la ejecución de las prescripciones"(2012a: 21). Desde esta perspectiva, el trabajo inicia cuando se pone en juego la subjetividad del que trabaja, el trabajo es aquello que la realidad exige al trabajador y lo que este realiza en consecuencia; mientras que la organización del trabajo es otra cosa: "nosotros denominamos organización del trabajo a la división del trabajo, el contenido de la tarea, el sistema jerárquico, las modalidades de gestión, las relaciones de poder, las cuestiones de responsabilidad, etc." (Dejours, 2001: 28).

Es necesario, en efecto, dejar clara esta distinción fundamental: empleo no es sinónimo de trabajo. En la medida en que trabajar implica la posibilidad de movilización subjetiva en aras de enfrentar las resistencias que opone lo real (y el sufrimiento implicado en ello), podríamos decir que el hecho de trabajar entraña siempre la posibilidad del crecimiento subjetivo. Sin embargo, el mismo Dejours plantea: "la evolución contemporánea de las formas de organización del trabajo, de gestión y de dirección de empresas se apoya, después del giro neoliberal, sobre principios que precisamentesugieren sacrificar la subjetividad en nombre de la rentabilidad y de la competitividad" (Dejours, 2012b: 32). Desde aquí va quedando claro que el malestar y los 
problemas de salud mental asociados al trabajo -destacados en Chile por la Encuesta Nacional de Empleo, Trabajo, Salud y Calidad de Vida de los Trabajadores y Trabajadoras (ENETS)- no se relacionan directamente con el hecho de trabajar, mas sí con las formas que toma la denominada organización (social y técnica) del trabajo contemporánea.

Aquí cabe argumentar que tal organización del trabajo contemporánea es una noción no del todo clara, pues la investigación referida a transformaciones en el mundo del trabajo, especialmente en el contexto latinoamericano que bien sistematizan de la Garza (2010) y Stecher (2014), da muestras de transformaciones incompletas y muchas veces de fuertes resabios tayloristas. Al respecto, Araujo (2014), basada en distintos autores locales, propone que en el caso chileno es necesario ponderar tales cambios en el contexto de un país poco industrializado, que ha sufrido cambios económicos e institucionales desde hace cuatro décadas, asociados a la desregulación de los mercados y la reducción del papel del Estado, al fortalecimiento de las empresas para definir las relaciones laborales y a un quiebre de la capacidad colectiva de negociación. La expansión de la flexibilización, el aumento de la externalización y la subcontratación, la expansión de los empleos temporales, trayectorias laborales más móviles y la diversificación de las modalidades y las condiciones de contratación, junto con la implementación de variados dispositivos del management que irrumpen en la relación entre seres humanos y trabajo, interpelando la subjetividad.

En síntesis, Araujo (2014) plantea que en Chile hay una desmesura laboral, expresada en una percepción generalizada de sobreexigencia y un incesante empuje a la acción, vivida con frecuencia como una transgresión a los propios límites. Desmesura, por cierto, asociada a las exigencias abrumadoras de consumo que hacen de la remuneración el principal índice de reconocimiento'.

La organización del trabajo contemporánea se orienta, en consecuencia, como lo enfatizan autores como Dejours (2012b), De Gaulejac (2008), Han (2014), entre otros, por al menos tres principios fundamentales: la rentabilidad, el rendimiento y la competitividad, que tiene a los trabajadores, como empresarios de sí, mejorando y/o adornando permanentemente su empleabilidad. Parafraseando a De Gaulejac (2016), la lucha de clases se ve reemplazada por una lucha por los lugares, una

1 Sumemos a esto que, en el caso chileno, la relación entre la carga financiera sobre el ingreso disponible de los hogares (RCI) es la más alta de la OCDE, alcanzando un $38 \%$, lo que quiere decir que alrededor de 4 de cada 10 pesos son destinados al pago de deudas (Fundación SOL, 2016). 
lucha puramente individual, una lucha que, para Han (2012), pierde en contenido y horizonte político.

\section{Psicodinámica del reconocimiento y el problema de la identidad}

De acuerdo con Dejours y Gernet, "el placer puede manifestarse en el trabajo cuando el sufrimiento puede transformarse en exigencia de trabajo para el Yo y pasar a ser una experiencia fundante de la identidad" (Dejours y Gernet, 2014: 32). Para que ello ocurra son necesarias tres condiciones: la primera, que el trabajador logre soportar el fracaso resultante de la confrontación con los límites de sus habilidades y recursos técnicos en el encuentro con lo real del trabajo. La segunda, que la movilización subjetiva del trabajador aporte algún nivel de solución a la encrucijada que ofrece lo real del trabajo, y la tercera, que la solución aportada por el trabajador, fruto de su esfuerzo subjetivo, sea reconocida por los demás.

La dinámica del reconocimiento, y por tanto sus efectos sobre la identidad -entendida por Dejours (1998) como pilar de la integridad psíquica- se ve fuertemente influenciada por la organización del trabajo, y por lo visto hasta aquí, posgiro neoliberal, el énfasis en la rentabilidad se impone sobre las consideraciones acerca de la subjetividad. Plantea Dejours: "Ia victoria del capitalismo a escala del planeta entero se plasma en la primacía teórica y práctica concedida a la empresa" (Dejours, 2012a: 10). La empresa como organización del trabajo que atraviesa y configura psiques y relaciones sociales.

Arrojados a esta lucha por los lugares que enfatiza De Gaulejac, son las bases de la solidaridad humana las que se ven erosionadas, y el vínculo social que implica el trabajo va siendo reducido a la competitividad más descarnada. Organizado bajo el signo de la empresa, la centralidad social del trabajo corre el riesgo de emerger productora y reproductora de violencias y de una civilidad cada vez más fragmentada (Dejours, 2012a). La experiencia clínica, plantea Dejours (2010), muestra cómo las expresiones patológicas en el trabajo contemporáneo -en buena medida resultado de la introducción masiva de métodos tomados de las ciencias de la gestión- cobran especialmente las formas de las patologías de la soledad y de la servidumbre, e incluso la del suicidio asociado al trabajo.

Por cierto, tal manera de organizar el trabajo merma considerablemente los espacios posibles para el reconocimiento, pues desde la jefatura $-y$ el juicio de utilidad-siempre será posible rendir aún más y desde los pares -y el juicio de belleza-: el éxito de unos descansa en el fracaso de otros. 


\section{Individualismo y patologías de la soledad}

"Las patologías de la soledad tienen como común denominador el aislamiento y la corrosión de los recursos defensivos colectivos contra los efectos patógenos del sufrimiento y de las obligaciones del trabajo. Estas formas de patología surgen esencialmente como consecuencia de la desestabilización del vínculo con el trabajo, debido a la introducción de métodos de management junto con los métodos de evaluación objetiva y cuantitativa de los rendimientos" (Dejours y Gernet, 2014: 87).

De este modo, la centralidad del trabajo sobre la vida psíquica -esto es, respecto de las posibilidades que el hecho de trabajar implica sobre el fortalecimiento identitario a través dela psicodinámica del reconocimiento, como la centralidad del trabajo sobre la vida social y sus posibilidades de convertirse en un medio para unir a los seres humanos en relaciones de cooperación-, primero se va obstruyendo y como resultado de ello nos enfrentamos hoy -por ejemplo en Chile- a algunos efectos significativos: "Para 2008, los problemas psicológicos se convierten en la primera causa de incapacidad transitoria (licencias médicas) entre los beneficiarios del sistema público. En las ISAPRE2, los trastornos mentales representaban en 2005 el 15,3\% del total de licencias, incrementando el 2008 su participación a 20,4 \%, convirtiéndose también en el grupo patológico de mayor peso relativo" (Miranda, Alvarado y Kaufman, 2012: 207). Los autores destacan asimismo la mayor concentración de mujeres en la explicación de este número.

\section{Sufrimiento ético y recurso a la virilidad}

El sufrimiento ético deriva de realizar en el trabajo acciones que evaluadas en un contexto diferente estarían reñidas con los preceptos morales de los mismos trabajadores. En palabras de Dejours (2006), se trata de cuando "buenas personas", esto es, aquellas que en circunstancias habituales de la vida diaria son regidas por un sentido moral a la hora de tomar decisiones y de emprender acciones, actúan en los marcos de la organización del trabajo como "ejecutoras del mal y la injusticia contra el prójimo" (Dejours, 2006: 73). Se trata de personas que sin ser perversas ni paranoicas se ven impulsadas a realizar trabajos sucios. Al encontrarse en tal circunstancia, la de hacer lo que no parece correcto hacer, las personas se enfrentan a la problemática del sufrimiento ético. La estrategia defensiva que se despliega en muchos de estos casos es la negación del sufrimiento: "Problemas éticos no hay. Es el trabajo y punto. Un trabajo como cualquier otro" (Dejours, 2006: 90). Para el autor, estas ideologías defensivas al 
servicio de la racionalización del mal se van configurando como virilidad: "Y así, para no correr el riesgo de no ser reconocidos como hombres por los otros hombres, para no perder los beneficios de pertenecer a la comunidad de hombres viriles (...) aceptan prestar su concurso al trabajo sucio" (Dejours, 2006: 89).

Sin embargo, la negación del sufrimiento no es exclusiva del sufrimiento de orden ético, sino de cualquier tipo de sufrimiento y la virilidad se juega en este mecanismo (Schneider, 2003). De este modo, el recurso a la virilidad se emparenta también con el mecanismo y las ideologías del aguante que han destacado diferentes estudios sobre masculinidades: la ideología del aguante es entendida como el arte de no escapar, de soportar lo que venga, una suerte de sacrificio no exento de dolor que sirve de sostén a la imagen y al honor viril (Abarca y Sepúlveda, 2005).

De este modo, la virilidad como negación del sufrimiento constituye un bloqueo a su subversión en placer y emerge como un obstáculo al desarrollo subjetivo en el enfrentamiento del ser humano con el trabajo. El sufrimiento se soporta, no se transforma.

Vistos estos elementos, pasemos a la discusión de los resultados levantados en los Conversatorios sobre salud mental y sufrimiento en el trabajo.

\section{Discusión de resultados}

Se presentan a continuación los principales resultados del análisis de los conversatorios, organizados en cinco categorías. La intención es proponer un diálogo entre la narración de las experiencias relevadas por los trabajadores y los conceptos de la Psicodinámica del trabajo abordados en el marco referencial.

\section{1. ¿Qué nos enferma?: La cuestión de la organización del trabajo}

Un primer punto que nos interesa relevar es la distinción que el discurso de los trabajadores hace entre trabajo y organización del trabajo. Desde aquí, trabajar no es el problema, sino cómo nos vemos forzados a hacerlo: "la forma de trabajar enferma a los trabajadores (...) La presión es muy alta; ponen exigencias a la gente difíciles de cumplir" (conversatorio trabajadores salud mental). La primera parte de la cita es elocuente; plantea de manera directa que los trabajadores enferman, mas no por su trabajo, sino por la forma que toma, por la manera en que está organizado. La segunda parte apunta a una especificación de la distinción hecha con antelación: la presión y las exigencias del trabajo que hacen difícil el cumplimiento de acuerdo con lo esperado. La cita invita a pensar la relación entre la 
dificultad para cumplir las exigencias -y la sensación de incumplimiento subsecuente- con la enfermedad. En términos dejourianos es posible interpretar la idea de que el sufrimiento y la enfermedad advienen cuando el esfuerzo de los trabajadores no es suficiente para enfrentar el obstáculo que ofrece lo real, quedando fuera de la posibilidad de reconocimiento. Sin embargo, cabe volver a distinguir: lo que aquí está en juego no es necesariamente el enfrentamiento con lo que Dejours denomina "real del trabajo", sino, más bien, el encuentro con lo real de la dominación social implicada en su organización.

Este último asunto va quedando claro al atender la siguiente cita: "tu jefatura te dice para qué y por qué estás aqui" (conversatorio trabajadores área salud). En consecuencia, la razón de estar y hacer en el trabajo es definida por otro, lo que se profundiza en la expresión: "se nos denomina ejecutores del programa" (conversatorio trabajadores área social). En esta línea, las exigencias, la meta y hasta las formas de cumplirla son puestas por otros. Si bien, en términos teóricos Dejours es explícito en plantear que no existe un trabajo puramente de ejecución, sino que, por el contrario, todo trabajo es creativo, en la experiencia de algunos trabajadores la organización del trabajo opera como un obstaculizador de la creatividad $y$, por tanto, como bloqueo a la potencialidad sublimatoria del trabajo. La experiencia de sentirse y vivirse como ejecutores habla de aquello, pues el ejecutor ha de prescindir de su propia interpretación del trabajo y ha de limitarse a seguir al pie de la letra la prescripción. Con esto, su subjetividad queda retenida y aquí parece radicar una importante fuente de sufrimiento, pues esta pura ejecución implica la invisibilización y/o la proscripción del uso del ingenio de los trabajadores en el quehacer diario: "usted no fue contratado para pensar" (conversatorio trabajadores área social).

Ahora bien, ante la presión y las exigencias del trabajo, algunos parecen no encontrar más opción que ponerse a su altura, y para lograrlo, dicen, "se empepan en la pega" (conversatorio de trabajadores eléctricos). Esto se refiere al recurso a los psicofármacos, a los que muchos trabajadores acuden con la intención de seguir funcionando, de salir victoriosos ante la presión, pues la expresión empeparse está asociada -en la jerga callejera de Santiago de Chile - a la ingesta de pastillas con un fin estimulanteanestesiante que en contextos de juerga permite seguir con el baile, y que llevado al contexto laboral implicaría algo parecido: "seguir dándole" a pesar del cansancio del cuerpo, desoír al cuerpo, cancelar sus sensaciones para conseguir los objetivos y las formas exigidas por la organización del trabajo. Tal recurso, orientado a rendir a toda costa, muchas veces disminuyendo la sensibilidad del cuerpo, podría ser asociado a estrategias defensivas virilizantes que consiguen de alguna manera disociar el 
pensamiento de la sensibilidad, poniendo por cierto al primero por encima del segundo.

Otras trabajadoras - que no cantan precisamente victoria-aguantan con el dolor de su cuerpo la acción que se exige para sostener el trabajo: "una, por ejemplo, llevaba una batea y se cayó, la patrona la hizo seguir trabajando y terminó en cama, hospitalizada" (conversatorio trabajadoras casa particular). Si bien esta expresión alude también al recurso al aguante, a tener que seguir trabajando a pesar del dolor del cuerpo (y por cierto también del sufrimiento psicológico), el tono no se vanagloria del triunfo, de la capacidad para sobreponerse y cumplir con las exigencias, sino que, por el contrario, asume un tono de denuncia, mostrando los efectos nocivos de desoír la sensibilidad del cuerpo en aras del rendimiento.

Las citas dan cuenta de dos maneras diferentes de enfrentamiento con las exigencias laborales: la primera, entendida en términos de virilización y la trampa que ella implica: creer que se triunfa cuando en rigor solo se aguanta la organización del trabajo, y la segunda, susceptible de ser leída en términos de una suerte de sometimiento silencioso a la misma. De una u otra forma solo se resiste, no se transforma la organización del trabajo.

El discurso continúa explicitando que en ocasiones la relación entre organización del trabajo y trabajadores toma la forma de la muerte: "en Victoria, un compañero no aguantó la presión y se suicidó" (conversatorio trabajadores eléctricos). La cita resulta alarmante, pues parece oponer dos alternativas radicales: o aguantar o morir, consigna que remite a la figura de un "héroe-masoquista" al que no le queda más que gozar la explotación. Se refuerza entonces la necesidad imperiosa de estrategias defensivas ante la organización del trabajo, que por limitadas que sean -en el sentido que no la transforman- resguardan de la desestabilización de la identidad, de la locura y la muerte. Considerando los aportes de Dejours a la comprensión del fenómeno del suicidio en situaciones de trabajo, es importante atender a lo que denomina patologías de la soledad (Dejours y Gernet, 2014), pues enfrentados individualmente a la presión y la exigencia de rendimiento, cada cual se bate con lo que puede, pues, "al final los trabajadores y trabajadoras están a su suerte en este país" (conversatorio trabajadores área salud). Es decir, cada cual se vale de su propia suerte, y la suerte, como sabemos, "está echada", se nos presenta al modo de un sino al que no queda más que entregarse. La asociación y la cooperación en aras de cambiar la suerte ceden a la soledad, el individualismo y la desesperanza. 
No obstante, el individualismo y el énfasis en el rendimiento de cada cual no son cuestiones naturales ni resultan del hecho de trabajar (Dejours, 2012a), sino que dependen de las formas de organizar el trabajo y las relaciones sociolaborales. A esto se suma la desprotección sindical chilena: "es una mafia la empresa (...) busca minar la confianza de los trabajadores hacia los dirigentes, busca a los delegados y los despide" (conversatorio trabajadores área salud). Operan prácticas de persecución e intimidación: se acosa a quienes hacen explícito y colectivo el malestar y se los despide, marcándolos como ejemplo que no es recomendable seguir, perpetuando el miedo entre los trabajadores. El miedo y la urgencia por rendir para ser bien evaluados emergen como enemigos de la confianza y la cooperación en el trabajo.

La organización del trabajo distorsiona los significados y pone trabas al pensamiento y a la acción colectiva, "fortalece el individualismo y a los trabajadores se los come el trabajo, quedan suicidados en vida" (conversatorio trabajadores área salud). Aquí, la noción de suicidados es relevante porque pone al suicida en entredicho como responsable único de su acto, implica, en cambio, la participación activa de un otro en el acto suicida y, en el marco de la cita expuesta, ese otro es develado como la organización del trabajo que fortalece el individualismo para que el trabajo se coma, uno a uno, a los trabajadores. Tales reflexiones obligan, en consecuencia, a pensar ya no solo las relaciones entre organización del trabajo, sufrimiento y enfermedad mental, sino, también, a considerar el hecho del suicidio como un posible analizador de dicho sufrimiento.

\section{Expresiones del sufrimiento: lo invisible de la (no) salud mental}

La irrupción y los efectos de la organización del trabajo en la psique y la salud mental de los trabajadores parece ser una cuestión silenciosa, difícil de advertir: "nosotros no tenemos herramientas para reconocer una patología mental" (conversatorio trabajadores eléctricos). La pregunta parece ser ¿cómo actuamos frente a algo que no estamos preparados para identificar, que pasa colado y que se vuelve cada vez más difícil de hablar? El sufrimiento psíquico y la psicopatología parecen operar como acechos silenciosos de la organización del trabajo contemporánea. En efecto, como vimos más arriba, las estrategias defensivas muchas veces logran acallar el sufrimiento, silenciar la problemática de las afecciones a la salud mental en el trabajo, pues aguantar y rendir parecen ser norma para sostenerse psíquica y efectivamente en él.

El silenciamiento de las problemáticas de salud mental en la esfera laboral cobra un matiz más intenso cuando la organización del trabajo y su obsesión por el rendimiento y la rentabilidad, sujetas a evaluaciones 
individualizadas del desempeño, van minando la comunicación y la confianza entre los trabajadores: "la desconfianza es general, decidimos no mostrar nuestros afectos" (conversatorio trabajadores salud mental). Con esta expresión los afectos se declaran exiliados del terreno laboral por considerarse peligrosos, pues su manifestación puede jugar en contra, se desconfía respecto de lo que cualquier oyente pueda hacer con ello, y como la desconfianza es general y por lo tanto inespecífica, cualquiera es desconfiable. Si los afectos no se muestran, si no circulan en la conversación de los compañeros de trabajo, si quedan desconectados de palabra, más difícil será percibir y encarar el sufrimiento desde perspectivas diferentes a las del aguante.

El discurso levantado en los conversatorios parece indicar que las vinculaciones que promueve la organización del trabajo contemporánea son principalmente de tipo instrumental o al menos libres de afecto: "acá no vengo a hacer amigos, vengo a trabajar" (conversatorio trabajadores área salud). Tan cierto como que nadie está obligado a trabar relaciones de amistad en el contexto laboral, es que el hecho de trabajar cooperativamente y poner en juego la inteligencia, la sensibilidad y la propia experiencia en una tarea compartida es una oportunidad quizá inmejorable para consolidar relaciones sociales satisfactorias y de mutuo reconocimiento. Sin embargo, parece posible hipotetizar que las experiencias laborales de muchos trabajadores participantes de los conversatorios hablan de desafección y de aislamiento.

Lo anterior confabula con el hecho de que el malestar psíquico juegue a las escondidas y se siga remitiendo a una problemática puramente individual, pues en la medida en que no se habla queda circunscrito al ámbito de responsabilidad de cada cual, lo que queda patente en la expresión: "uno debe detectar cuando uno está dañado" (conversatorio trabajadores área transporte). La cita hace posible pensar, en consecuencia, que el cuidado es tarea de cada quien, lo que en buena medida implica que la organización del trabajo tiene licencia para desentenderse de ello. Cabe destacar que la frase resalta la condición individualista al marcar en dos ocasiones la expresión "uno": es "uno" el que debe porque "uno" está dañado. Sin embargo, tal responsabilidad no encuentra mucha salida, pues no hay claridad de qué hacer una vez que el daño se detecta. Al respecto, Dejours (2012a) es explícito al proponer que el actual incremento en las consultas psicoterapéuticas se relaciona con la crisis de la solidaridad y que, al mismo tiempo, la acción clínica muchas veces queda sin salida política.

Lo que se va configurando es que la necesidad de ocultar el sufrimiento se tolera hasta que no se puede más, se lleva hasta los límites que rayan con la muerte: "me han confesado algunos trabajadores que han estado a 
punto de matarse, a punto de tocar los cables" (conversatorio trabajadores eléctricos). Al respecto, no podemos pasar por alto el hecho de que el sufrimiento se comunica en clave de confesión, como si fuera un pecado, ¿contra qué mandamiento, contra qué divinidad, buscando qué redención? Al parecer se confiesa la culpa por la ideación suicida, más la culpa es referida, otra vez, sobre el trabajador. Con Han (2014) podríamos pensar en la confesión y la culpa ocupando el lugar de la rabia y la rebelión en la sociedad del rendimiento, en la que cada trabajador está conminado a ser su propio jefe.

Sin embargo, por críticos que podamos ser de la noción de confesión, no podemos dejar de concederle valor, pues moviliza la puesta en palabras del sufrimiento que bien podría operar en lugar del acto suicida $y$, por qué no, pensar que esta confesión pueda marcar en la reflexión de los trabajadores un punto de inflexión: "nunca había pensado que el suicidio podía tener que ver con el trabajo" (conversatorio trabajadores eléctricos). ¿Y cómo pensarlo si se insiste en explicar el suicidio como asunto individual? No obstante, la expresión "tocar los cables", en el caso de trabajadores eléctricos, constituye una imagen que invita a visualizar las relaciones entre trabajo, sufrimiento y suicidio.

\section{Individualismo y soledad: quiebres en la dinámica del reconocimiento}

Desde esta perspectiva, el suicidio se va configurando como una expresión extrema del sufrimiento y, como lo plantea Dejours (2010), esto tiene relación con la soledad y el aislamiento que los trabajadores comienzan a experimentar como producto de la irrupción de mecanismos manageriales para el control de la gestión. Expuestos a la soledad, es la dinámica de la identidad la que corre peligro, pues el trabajador queda desconectado de sus pares $y$, por mucho que sostenga la conexión con la tarea, queda privado de la posibilidad del reconocimiento.

Al respecto, veamos la siguiente cita: "la identidad que me he ido formando en parte es lo que he ido haciendo" (conversatorio de trabajadores salud mental). En esta cita se juega parte de la teoría del reconocimiento presente en psicodinámica del trabajo. Ahora bien, el paso fundamental para el retorno al registro de la identidad de aquello que se hace, es el reconocimiento que de ese hacer realiza un otro. En consecuencia, si las relaciones sociolaborales están truncadas, si el vínculo con el colectivo de trabajo está interrumpido, se castra la posibilidad del reconocimiento $y$, con ello, el desarrollo subjetivo en el que potencialmente podría participar el trabajo. 
Respecto de lo anterior, los trabajadores manifiestan que muchas veces "da lo mismo quien haga lo que haga mientras se haga" (conversatorio trabajadores salud mental). Lo importante para la organización del trabajo es que el trabajo sea realizado, pero resulta menos relevante la fuerza humana que hay detrás, siendo borrado el aporte singular del trabajador no reconociéndose su aporte específico y, con ello, su propia inteligencia puesta en juego en el ejercicio del trabajo. De este modo, se interrumpe la dinámica del reconocimiento y la identidad, coartándose la posibilidad de transformar el sufrimiento en placer en el trabajo.

Quizá justamente por lo anterior la demanda cobra una expresión tan clara: "busco respeto y que me reconozcan" (conversatorio de trabajadores casa particular). Aquí el respeto y el reconocimiento son leídos a través de conceptos dejourianos, es decir, tienen que ver con el trabajo realizado. Es la valorización del trabajo lo que termina por repercutir a nivel de la identidad del trabajador. El reconocimiento al hacer se expresa en ocasiones como el "reconocimiento de tu aporte como persona a un fin mayor, a la sociedad" (conversatorio trabajadores área salud). En el horizonte subjetivo de los trabajadores parece encontrarse esta necesidad, la de que el trabajo tenga sentido y se inscriba en el aporte al logro de un "fin mayor", el trabajo como cooperación con algo que va más allá de él mismo. Esto es lo que parece desdibujarse cuando el hecho de trabajar queda reducido, como efecto de la organización del trabajo, a "puro empleo", en el intercambio entre fuerza de trabajo y dinero, donde se extravía el horizonte comunitario del esfuerzo subjetivo y la tarea. Proponemos que, en esta reducción del trabajo al empleo, se le quita al trabajo su potencialidad emancipatoria en su doble centralidad: sobre la subjetividad y sobre las relaciones sociales.

\section{Hacer lo que no me parece correcto: el tema del sufrimiento ético}

En ocasiones, cumplir con el trabajo como es pedido implica ir en contra de lo que los trabajadores estiman correcto; sin embargo, hay que hacerlo: "tenemos casos de secretarias que deben cobrar cuentas a familiares de fallecidos que pasaron harto tiempo con los pacientes que después fallecen, y a conocen a las familias y luego, tener que cobrar 4, 5, 10 millones de pesos es supercomplicado" (conversatorio trabajadores área salud). El sufrimiento vivido aquí es de orden ético, la cita expresa la obligatoriedad de hacer una suerte de trabajo sucio, indeseable, incluso cruel, que seguramente exige una buena dosis de insensibilización para poder llevarse a cabo. La cita específica refiere a situaciones en las que deben enfrentarse a personas y a fuertes montos de emoción. 
En otros casos, los ribetes del asunto implican infligir dolor a los compañeros de trabajo: "soy yo la que tiene que comunicarles el despido, la verdad es que eso no me deja dormir" (conversatorio trabajadores área transporte). En este caso, es una trabajadora que ocupa un mando medio la que se ve impelida a encarnar una decisión de la empresa y a enfrentar la tarea de comunicar la "desvinculación". Como corolario, es ella la que pierde el sueño, la que carga en su conciencia la eliminación de los trabajadores. Comunicar el despido implica para esta trabajadora corporizar y poner en escena una actuación que la contraría y que le toca interpretar aun en contra de su propio sentir. En este caso, prestar el cuerpo a la organización del trabajo trae la consecuencia del insomnio, de la intranquilidad psíquica y corporal.

\section{El ítem de autocuidado: el cuidado como responsabilidad individual}

Ante la situación hasta aquí expuesta, aunque ni siquiera en todos los casos, "hay un ítem de autocuidado" (conversatorio trabajadores salud mental), generalmente materializado en unos cuantos pesos para realizar alguna actividad: "algo de autocuidado" (conversatorio trabajadores salud mental). Algo, o sea, cualquier cosa; un asado, una obra de teatro, técnicas de respiración o lo que fuere. Lo relevante del concepto parece estar en lo de auto, es decir, a cargo de cada cual o a lo sumo de cada equipo, en fin: responsabilidad de los trabajadores y no de la organización del trabajo. Dicho esto, cabe destacar que generalmente las actividades de autocuidado consisten en acciones que distraen del trabajo en lugar de abordarlo, que lo sacan del foco del análisis como agente generador de sufrimiento, que no promueven necesariamente la circulación de la palabra. Se trata por lo general de "desconectarse" del trabajo, suponiéndolo un entorno, una exterioridad del psiquismo, un ambiente del cual podemos retirarnos, negando con ello su subjetivación, su incorporación en psiques y cuerpos.

Sin embargo, dicen los trabajadores, "tenemos la necesidad de ser escuchados, nos quedamos sin voz y sin esperanza, con la sensación de que no hay posibilidades de cambiar; hay un alto así de currículums esperando" (conversatorio trabajadores salud mental). La cita refiere a una necesidad que se va haciendo manifiesta: la de hablar y ser escuchados, la de generar espacios protegidos para reflexionar en torno a lo que hacemos y a lo que nos pasa con aquello que hacemos, de recuperar la voz y, con ello, la posibilidad de pensar colectivamente el quehacer. Esta falta de voz parece tener relación con la invisibilización de la subjetividad movilizada en el trabajo, pues la desesperanza radica -al menos en lo que esta cita manifiestaen la falta de identidad personal, en la sensación de que los trabajadores 
son objetos fácilmente intercambiables y que cualquier intento de transformación puede significar el despido: "hay un alto así, de currículos esperando". Aquí el que tiene que cambiar es el trabajador, resignando toda posibilidad de transformación de la organización del trabajo.

En este marco cobra sentido lo de autocuidado, entendido al modo de una suerte de adaptación defensiva que cada cual realiza respecto de la organización del trabajo, la que emerge como inamovible y ciega a la singularidad de los trabajadores, quienes se experimentan a sí mismos como fácilmente reemplazables.

\section{Conclusiones}

Ofrecemos aquí dos ideas que, más que concluir, abren posibilidades de investigación.

La primera. Actualmente, en Chile se encuentra en vigencia el Protocolo de vigilancia de riesgos psicosociales en el trabajo, en calidad de ley. "Este protocolo tiene alcance y aplicación en todas las empresas, organismos públicos y privados que se encuentren legal y formalmente constituidas, con independencia del rubro o sector de la producción en el cual participen, o del número de sus trabajadores" (Ministerio de Salud, 2013). El objetivo principal de este Protocolo es "identificar la presencia y nivel de exposición a riesgos psicosociales al interior de una organización" (Ministerio de Salud, 2013).

El Protocolo constituye, sin duda, un avance en lo que respecta a la posibilidad y necesidad de pensar las relaciones entre salud mental y trabajo. Sin embargo, al estar elaborado a la luz de un paradigma epidemiológico y factores de riesgo externos, no necesariamente considera los esfuerzos de los trabajadores por levantar estrategias defensivas que van, al mismo tiempo, configurando subjetividades laborales ni el impacto de esto en la producción de relaciones sociales, ya sea dentro de las empresas o fuera de ellas. (Dejours, 2012a, b).

No obstante, la experiencia de los trabajadores relevada en el proceso de los "Conversatorios sobre salud mental y sufrimiento en el trabajo" desarrollada en este texto, da cuenta, justamente, de las relaciones entre trabajo y subjetividad y entre trabajo y relaciones sociales. En definitiva, que el trabajo no es simplemente un entorno capaz de exponernos a determinados estresores externos, sino, más bien, parte constituyente del psiquismo de quienes trabajan y de las relaciones que producen.

Desde aquí parece relevante, al menos para la realidad chilena, avanzar en la dirección en que Julio Neffa lo ha hecho en Argentina, es decir, buscar 
posibles integraciones entre las perspectivas de los Riesgos Psicosociales en el Trabajo y las teorías subjetivas al respecto, en particular, como lo ha hecho también con la psicodinámica del trabajo (Neffa, 2015).

Entonces, al tiempo que medir la exposición a riesgos y esforzarnos en disminuir su incidencia, tendremos que tratar de comprender los efectos de la organización del trabajo sobre la subjetividad y las relaciones sociolaborales, esto es, atender a cómo el trabajo es subjetivado y cómo las relaciones sociolaborales van estructurando otras relaciones sociales. Lo plantea Dejours (1998, 2014): el cuidado de las estrategias de defensa adquiridas con esfuerzo en el trabajo no se limita al escenario laboral, las defensas van constituyendo el psiquismo y los cuerpos de los trabajadores $y$, por tanto, traspasan los muros de la empresa y marcan todas las relaciones sociales, especialmente las familiares.

En síntesis: el trabajo no es un entorno del que se entra y se sale, es constitutivo de psiquis y cuerpos, por lo que es necesario y urgente reasumir la centralidad del trabajo, la doble centralidad del trabajo: la psíquica y la social.

La segunda. El asunto de la virilidad. Asumida la doble centralidad del trabajo viene de cajón la siguiente pregunta: ¿qué tipo de subjetividad y qué tipo de relaciones sociales produce la denominada organización del trabajo contemporánea, posgiro neoliberal? Mi propuesta en ciernes es más o menos la siguiente: si lo que vale es rendir y rentar, si la manera de hacerlo es la competencia y el gerenciamiento de sí, si lo importante es la lucha individual por una posición, entonces, el sufrimiento es un problema. Si el sufrimiento es un problema se torna necesario negarlo y al negarlo se lo cancela como exigencia de trabajo para la psique, como potencial de crecimiento subjetivo. Cancelar el sufrimiento es en buena medida cancelar el cuerpo, pues es en el cuerpo en que se vivencian el sufrimiento y la vulnerabilidad; el límite. Propongo que la desmesura laboral que bien describe Araujo (2014) como clave de la prueba que el trabajo constituye para la subjetividad de los trabajadores en Chile, expresada en una percepción generalizada de sobreexigencia y un incesante empuje a la acción, vivida con frecuencia como una transgresión a los propios límites, es una invitación a lo que llamo virilización del cuerpo subjetivo, que consiste básicamente en un doble movimiento de desensibilización del cuerpo erógeno y de desafectación del pensamiento como formas de negar el sufrimiento.

Si lo que interesa es aportar al desarrollo de las Clínicas del trabajo, parece central considerar este par de ideas, que, por cierto, más abren que cierran y se enfocan justamente en la necesidad de escuchar y atender 
el sufrimiento en el trabajo y las defensas que contra este levantan los trabajadores.

\section{Referencias Bibliográficas}

- ABARCA, Humberto y SEPÚlVEDA, Mauricio (2005). Barras bravas. Pasión guerrera. Territorio, masculinidad y violencia en el fútbol chileno. (pp. 145-170). En: FERRÁNDIZ, F y FEIXA, C (Eds.) Jóvenes sin tregua: culturas y políticas de la violencia. Barcelona. Anthropos.

- $\quad$ ARAUJO, Kathya (2014). La desmesura y sus sujetos. El trabajo en el caso de Chile. (pp. 277-298). En: STECHER, A y GODOY, L (Eds.) Transformaciones del trabajo, subjetividad e identidades. Chile: RIL Editores.

- DE GAULEJAC, Vincent (2008). El costo de la excelencia. Conferencia en Buenos Aires. Mimesis. Disponible en Internet: http://mastor.cl/blog/wpcontent/uploads/2015/05/Gaulejac-El_costo_de_la_excelencia.-De-Gaulejac.Conferencia-2008.-pdf.pdf. Consultado 10.10.2016

- DE GAULEJAC, Vincent. (2016). El trabajo: las razones de la cólera. Conferencia central III Simposio TAS (Trabajo, actividad y subjetividad). Córdoba (Arg.). Memoria digital en proceso de publicación.

- DE LA GARZA, Enrique (2010). Hacia un concepto ampliado de trabajo. $1^{\text {a }}$ ed. Méjico DF: Antrophos.

- DEJOURS, Christophe (2012a). Trabajo vivo. Tomo I. Sexualidad y trabajo. $1^{\mathrm{a}}$ ed. Buenos Aires: Topía Editorial.

- DEJOURS, Christophe (2012b). Trabajo vivo. Tomo II. Trabajo y emancipación. 1a ed. Buenos Aires: Topía Editorial.

- DEJOURS, Christophe (1998). De la psicopatología a la psicodinámica del trabajo. (pp. 23-76). En: DESSORS y GUIHO-BAILLY, compiladores. Organización del trabajo y salud. Buenos Aires: Grupo Editorial Lumen.

- DEJOURS, Christophe (2006). La banalización de la injusticia social. Buenos Aires: Topía editorial.

- DEJOURS, Christophe (2001). Trabajo y desgaste mental. Buenos Aires-Méjico: Grupo editorial Lumen.

- DEJOURS, Christophe y GERNET, Isabelle (2014). Psicopatología del trabajo. Buenos Aires: Miño y Dávila.

- FLORES, Rodrigo y NARANJO, Carolina (2013). Análisis de datos cualitativos: el caso de la grounded theory. (pp. 75-113). En: CANALES, M (coordinador). Escucha de la escucha. Análisis e interpretación en la investigación cualitativa. Santiago de Chile: LOM Ed.

- FUNDACIÓN SOL, Chile. (2016). El brutal endeudamiento de los chilenos y la desposesión salarial. Disponible en internet: http://www.fundacionsol. cl/2016/03/el-brutal-endeudamiento-de-los-chilenos-y-la-desposesion-salarial/. Consultado 07.10.2017

- HAN, Byung-Chul (2014). Psicopolítica. Barcelona: Herder. 
- CHILE. Ministerio de Salud. Protocolo de vigilancia de riesgos psicosociales en el trabajo, 2013. Gobierno de Chile. División de Políticas Públicas Saludables y Promoción Subsecretaría de Salud Pública.

- MIRANDA, Gonzalo, ALVARADO, Sergio y KAUFMAN, Jay. (2012). Duración de las licencias médicas FONASA por trastornos mentales y del comportamiento. En: Revista Médica de Chile. Vol. 140, № 2. Santiago de Chile: Sociedad Médica de Santiago.

- NEFFA, Julio César (2015). Los riesgos psicosociales en el trabajo. Contribución a su estudio. Edición digital. Buenos Aires: Ceil-Conicet.

- SCHNEIDER, Monique (2003). Genealogía de lo masculino. Buenos Aires: Paidós.

- STECHER, Antonio (2014). El campo de investigación sobre transformaciones del trabajo, identidades y subjetividad en la modernidad contemporánea. Apuntes desde Chile y América Latina. (pp. 19-76). En: STECHER, A y GODOY, L (Eds.) Transformaciones del trabajo, subjetividad e identidades. Santiago de Chile. RIL Ed.

Para citar este artículo:
Zuleta, Pablo. (2018). Encuentro entre Christophe Dejours y trabajadores chilenos. Conversatorios sobre salud mental y sufrimiento en el trabajo. Teuken Bidikay Vol. 9 № 12. Medellín: Politécnico Colombiano. Pp. 135-152

Ferrocarril de Costa Rica

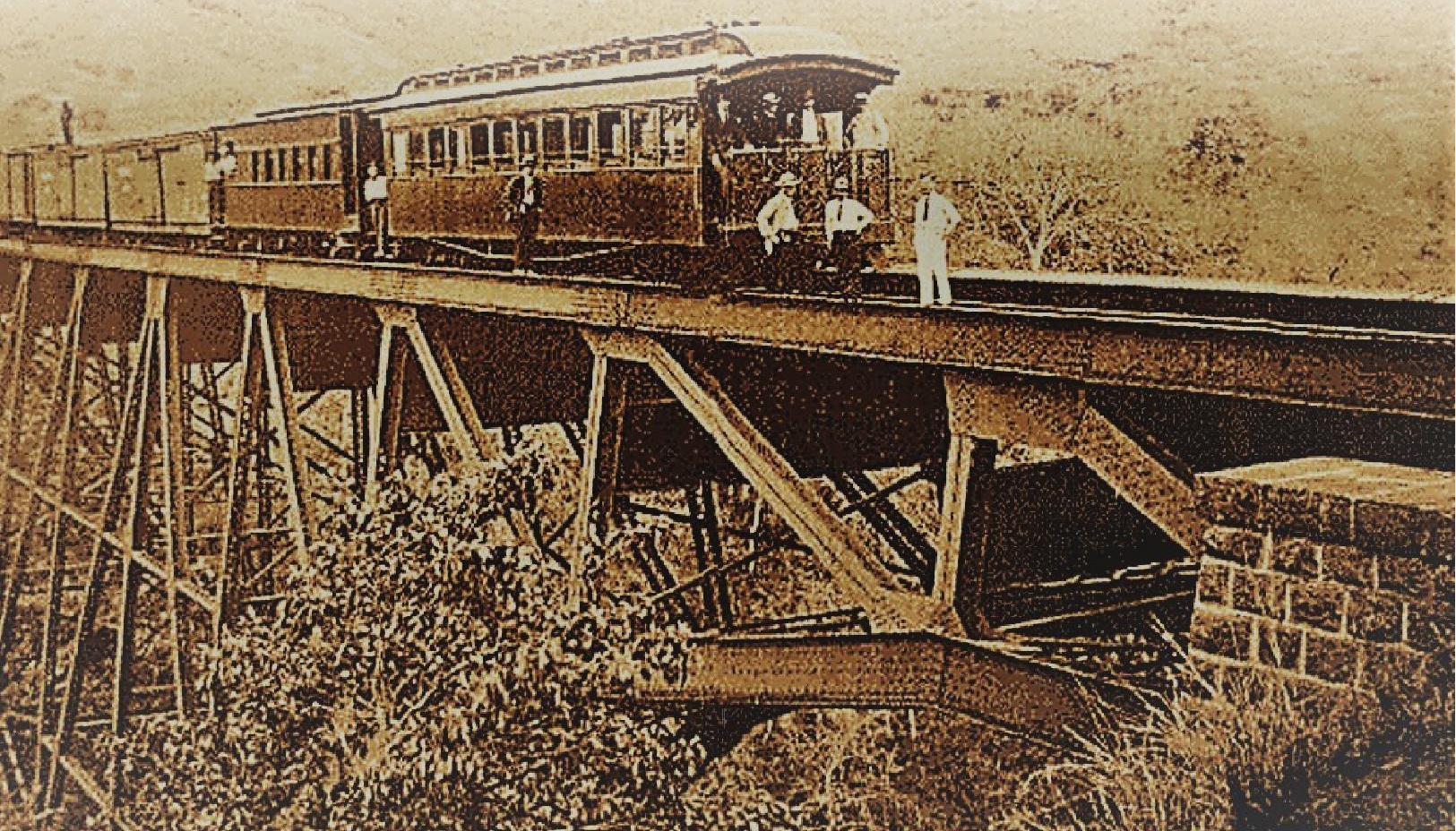

